\title{
Perception of predictive testing for Huntington's disease by young women: preferring uncertainty to certainty?
}

\author{
Marleen Decruyenaere, Gerry Evers-Kiebooms, Herman Van den Berghe
}

\begin{abstract}
Opinions on the implications of predictive testing for Huntington's disease were evaluated in a group of 169 women (aged 21-35 years) with interest in psychosocial issues, but with no special pre-existing knowledge or training in genetics.

Predictive testing for Huntington's disease (HD) is considered to be a test case for predictive testing for other late onset diseases, monogenic as well as multifactorial disorders. In the hypothetical situation of having a $\mathbf{5 0 \%}$ risk for developing HD, about half of the group expressed interest in a predictive test. As to the question of giving results of predictive tests to third parties, the group would be very reluctant to inform the employer or the insurer, but not their own family. Prenatal testing for late onset diseases was considered acceptable by half of the women; only one quarter of the total group would terminate a pregnancy of a child that might develop a late onset disease.
\end{abstract}

The assessment of attitudes towards predictive testing was carried out within the context of a global evaluation of perceived advantages and disadvantages of genetic counselling. The attitudes towards predictive testing were systematically associated with perceiving 'having more certainty about the future' as an advantage of genetic counselling and with rejecting 'knowing everything in advance' as a disadvantage.

( $\mathcal{F}$ Med Genet 1993;30:557-61)

Predictive DNA testing has become a reality for several autosomal dominant late onset diseases, such as myotonic dystrophy and Huntington's disease (HD). As a consequence a unique situation has emerged in that one is able to inform asymptomatic persons that they will get a severe disease, for which there is no cure, with an onset years or even decades after the communication of the test result. It is highly probable that predictive tests for other late onset diseases will be available in the near future (for example, for various forms of cancer, cardiovascular diseases, and psychiatric disorders). It is the main aim of the present paper to assess the attitudes and opinions of young women about predictive testing for Huntington's disease.

This evaluation was carried out within the context of the women's perception of the advantages and disadvantages of genetic coun- selling. According to professionals, genetic tests give people more autonomy and control over their future, especially over procreation. It gives them the opportunity of preventing suffering in children and parents. ${ }^{12}$ Predictive testing for late onset diseases often resolves the stressful uncertainty about becoming ill or not, and may help in planning the future more easily. Genetic tests have, however, also entailed negative feelings, such as anxiety and depression, guilt and grief. ${ }^{3-5}$ Positive results of carrier testing may lead to stigmatisation or discrimination. ${ }^{67}$ Knowing with certainty that one will develop a serious late onset disease may be like living with a 'time bomb'. Even in the case of a negative result of a predictive test, maladaptive coping has been observed. ${ }^{8}$

Opinions about predictive testing have not previously been studied in the general population; they have only been evaluated in persons with a high risk of developing a specific disease..$^{9-11}$ In the period immediately preceding the actual test programme in Belgium, $66 \%$ of a group of persons at risk for HD reported that they would request the predictive test. ${ }^{9}$ The proportion of persons actually entering the predictive testing programme in Belgium is smaller, however. This finding is in keeping with the experience in other centres.

The present paper evaluates young women's intentions with regard to predictive testing as well as their opinions about informing third parties of the results of such tests. The problems of balancing the person's right to privacy against the rights of third parties, such as relatives at risk, insurance companies, and employers, are well known in clinical genetics. ${ }^{12-15}$ This is one of the most difficult issues in the ethics of genetic counselling. Wertz and Fletcher ${ }^{16}$ stated that "geneticists in all nations are vividly aware of the potential damage from third party access to results, especially access by insurance companies". The same authors also reported a reluctance of geneticists to giving access to results of genetic tests to employers. Moreover, genetic counselling does not only inform people about their own risk, but also (directly or indirectly) about their brothers' and sisters' risk. Therefore, we also evaluated the young women's opinion with regard to informing relatives.

\section{Methods}

QUESTIONNAIRE

The description of the questionnaire is limited to the variables that are discussed in the present paper. A detailed description of the entire 
Table 1 Agreement and disagreement* with the advantages and disadvantages of genetic counselling $(n=169)$.

\begin{tabular}{|c|c|c|c|}
\hline & Agree $(\%)$ & $?(\%)$ & Disagree (\%) \\
\hline \multicolumn{4}{|l|}{ So called advantages } \\
\hline \multicolumn{4}{|l|}{ Having more control over the health of the } \\
\hline \multicolumn{4}{|l|}{ Preventing suffering of the parents of a } \\
\hline handicapped child & $66 \cdot 8$ & $11 \cdot 3$ & 21.9 \\
\hline Preventing suffering of the handicapped child & $62 \cdot 1$ & $16 \cdot 0$ & 21.9 \\
\hline Having more certainty about the future & $61 \cdot 6$ & $13 \cdot 0$ & $25 \cdot 4$ \\
\hline \multicolumn{4}{|l|}{$\begin{array}{l}\text { Being able to plan better for the future } \\
\text { Making available more financial resources for }\end{array}$} \\
\hline $\begin{array}{l}\text { other aspects of health care by means of } \\
\text { prevention }\end{array}$ & $52 \cdot 6$ & $21 \cdot 3$ & $26 \cdot 0$ \\
\hline \multicolumn{4}{|l|}{ So called disadvantages } \\
\hline The danger of stigmatisation & $62 \cdot 2$ & $10 \cdot 7$ & $27 \cdot 2$ \\
\hline \multicolumn{4}{|l|}{ The possibility of getting information about } \\
\hline \multicolumn{4}{|l|}{ The danger of misuse of scientific genetic } \\
\hline research, for instance to create supermen & $55 \cdot 7$ & $10 \cdot 1$ & $34 \cdot 3$ \\
\hline Anxiety at undergoing a genetic check up & $53 \cdot 2$ & $13 \cdot 6$ & $33 \cdot 2$ \\
\hline The danger of making people unhappy & $48 \cdot 0$ & $13 \cdot 0$ & $39 \cdot 0$ \\
\hline Knowing everything in advance & $42 \cdot 0$ & 11.8 & $46 \cdot 2$ \\
\hline
\end{tabular}

*'Disagree' $=$ categories 1 and 2 on the scale.

'?' = category 3 (=I don't know).

'Agree' $=$ categories 4 and 5 on the scale.

questionnaire can be found in Decruyenaere et al. ${ }^{17}$

\section{Perceived advantages and disadvantages of genetic counselling}

We asked to what extent the subjects agreed or disagreed with possible advantages and disadvantages of genetic counselling on a five point scale $(1=$ strongly disagree, $2=$ mildly disagree, $3=$ don't know, $4=$ mildly agree, $5=$ strongly agree). The formulation of these pros and cons was inspired by a survey of the VSOP, a patient organisation for genetic diseases in the Netherlands (see table 1 for a list of the advantages and disadvantages).

\section{Attitudes towards predictive testing}

We presented a descriptive text about HD (appendix 1). The possibility of a predictive test was explained; we simplified the situation and did not mention the limitations of the linkage test. Then we asked about their intentions to request the predictive test in the hypothetical situation of being at $50 \%$ risk for HD. We also assessed the acceptability of prenatal testing for late onset diseases (appendix 2) and their attitudes towards pregnancy termination, should they be pregnant with "a child that would get an adult onset disease (at 35 to 50 years), involving physical and mental deterioration" (appendix 3). Finally, we asked about informing third parties about the result of a predictive test and about informing their brothers and sisters about their increased risk (see Results for the answers).

Table 2 Sociodemographic description of the sample $(n=169)$.

\begin{tabular}{lclr}
\hline Age & & Marital status \\
$21-25$ years & $28(16.6 \%)$ & Married & $101(59.8 \%)$ \\
$26-30$ & $54(31.9 \%)$ & Unmarried, having a relationship & $29(17 \cdot 1 \%)$ \\
$31-35$ & $87(51.5 \%)$ & Unmarried, no relationship & $27(16.0 \%)$ \\
Educational level & & Divorced & $10(5.9 \%)$ \\
Primary school & $1(0.6 \%)$ & Widowed & $2(1.2 \%)$ \\
< High school & $38(22.5 \%)$ & Religious practice & \\
High school & $60(35.5 \%)$ & Not religious & $32(18.9 \%)$ \\
PHigh school & $56(33.1 \%)$ & Religious, sporadic practice & $53(31.4 \%)$ \\
University degree & $11(6.5 \%)$ & Religious, irregular practice & $42(24.9 \%)$ \\
No information & $3(1.2 \%)$ & Religious, regular practice & $23(13.6 \%)$ \\
& & Religious, frequent practice & $17(10.1 \%)$ \\
& & No information & $2(1.2 \%)$ \\
\hline
\end{tabular}

The variables were measured by means of multiple choice questions and the data were analysed by means of SAS (1988). To study the relationship between the attitudes towards predictive testing and the variables, which were measured on an ordinal scale, we used the Kendall rank correlation coefficient (tau).

SAMPLE

The sample was a subgroup of the entire adult student population who followed courses at the Centre for Family Science in Brussels in 1990. The courses take up seven hours a week for three years and cover topics such as psychology, education, sociology, and law. These participants had no special pre-existing knowledge of or training in genetics. Because the focus of this paper is on predictive testing for late onset diseases, the subgroup of women was restricted to those no older than 35 years $(n=169)$. In this age group, the number of male students was so small that we did not include them.

\section{Results}

DESCRIPTION OF THE SAMPLE

The mean age of the women was 30.13 years (table 2). The group covered the whole range of educational levels; however, compared with the general population the higher levels were slightly overrepresented. About half of the group (56\%) had a job, $31 \%$ were housewives, and $12 \%$ were unemployed. Most of them were married $(60 \%)$ or had a partner $(17 \%)$. About $71 \%$ of the respondents had at least one child; the average number of children was two. Thirty-five percent were still considering a(nother) pregnancy. The majority of the respondents were religious (Roman Catholic), with varying degrees of church attendance.

PROS AND CONS OF GENETIC COUNSELLING

The agreement and disagreement with the socalled advantages and disadvantages of genetic counselling is presented in table 1 . The categories 'strongly agree' and 'mildly agree' are grouped into one category and the same was done for 'strongly disagree' and 'mildly disagree'. When comparing advantages and disadvantages, $62 \%$ thought that the pros of genetic counselling outweighed the cons.

ATTITUDES TOWARDS PREDICTIVE TESTING

About half of the group (53\%) expressed interest in a predictive test in the hypothetical situation of being at $50 \%$ risk for developing $\mathrm{HD}$ in the future, while $25 \%$ answered that they were not interested. A rather large proportion $(16 \%)$ did not know and $6 \%$ gave no answer. Interest in predictive testing for HD was significantly correlated with agreeing with most of the advantages and disagreeing with the disadvantages of genetic counselling (appendix 4). We only discuss the highest correlations. We found a correlation of tau $=$ $-0.42(\mathrm{p}<0.0001)$ with 'knowing everything 
Table 3 Attitudes towards informing third parties about the results of a predictive test $(n=169)$.

\begin{tabular}{lccccc}
\hline & Yes & $\begin{array}{c}\text { Only with } \\
\text { permission }\end{array}$ & No & Missing & Total \\
\hline Partner & $73(43 \cdot 2 \%)$ & $78(46 \cdot 2 \%)$ & $3(1 \cdot 8 \%)$ & $15(8 \cdot 9 \%)$ & $169(100 \%)$ \\
Children & $30(17 \cdot 8 \%)$ & $97(57 \cdot 4 \%)$ & $13(7 \cdot 7 \%)$ & $29(17 \cdot 2 \%)$ & $169(100 \%)$ \\
GP & $80(47 \cdot 3 \%)$ & $64(37.9 \%)$ & $4(2 \cdot 4 \%)$ & $21(12.4 \%)$ & $169(100 \%)$ \\
Employer & $1(0.6 \%)$ & $13(7 \cdot 7 \%)$ & $108(63 \cdot 9 \%)$ & $47(27 \cdot 8 \%)$ & $169(100 \%)$ \\
Insurer & $2(1.2 \%)$ & $18(10 \cdot 7 \%)$ & $104(61 \cdot 5 \%)$ & $45(26.6 \%)$ & $169(100 \%)$ \\
\hline
\end{tabular}

in advance': people expressing interest in predictive testing for HD were less likely to think that knowing everything in advance is a possible disadvantage of genetic counselling. Agreeing that 'having more certainty about the future' and 'being better able to plan for the future' are advantages was also associated with a positive attitude towards predictive testing for $\mathrm{HD}$ (tau $=0.33$ and tau $=0.35$ respectively; $\mathrm{p}<0.0001)$. We found no association with sociodemographic variables.

Prenatal testing to predict whether a child will have a late onset disease was considered 'acceptable' by $50 \%$ of the group and 'not acceptable' by $32 \%$. Ten percent did not know and $7 \%$ did not answer. Here again, we found significant correlations between agreeing with the advantages and disagreeing with the disadvantages (appendix 4). Accepting prenatal testing was associated with agreeing that 'having more certainty about the future' is an advantage (tau $=0.36, p<0.0001$ ) and with rejecting 'knowing everything in advance' as a disadvantage of genetic counselling (tau $=-0.35, \mathrm{p}<0.0001)$. We found no association with sociodemographic variables.

Twenty-eight percent of the total group (44\% of those who considered prenatal predictive testing acceptable) would terminate the pregnancy should they be pregnant with 'a child with a serious late onset disease', $67 \%$ would not terminate, and $5 \%$ were undecided. The respondents who more frequently practised religion were more likely to reject abortion in this situation (tau $=-0 \cdot 16, \mathrm{p}<0.05)$. The intention to terminate the pregnancy was most strongly correlated with considering 'prevention of suffering of the parents' as an advantage (tau $=0.32, \mathrm{p}<0.0001$ ) (appendix 4).

We asked the respondents who they thought should be allowed to receive information about the results of a predictive test (table 3 ). It is striking that a very low proportion of the women would allow the employer and the insurer to be informed. The more frequently practising religious respondents were more likely to permit (unconditionally) their partner and their children to be informed (tau $=0 \cdot 18$, $\mathrm{p}<0.05$ and tau $=0.15, \mathrm{p}<0.05$ respectively). The higher the level of education, the more often they would inform the children $(\operatorname{tau}=0 \cdot 16, \mathrm{p}<0.05)$. We further confronted them with the hypothetical situation of being

Table 4 Informing brothers and sisters about their genetic risk $(n=169)$.

I myself would give them all necessary information

I would refer them to a genetics centre to seek the information they need

I would not inform them. The genetics centre should contact them

I do not think it is necessary that my brothers and sisters are informed

No answer informed during genetic counselling about the increased risk to their brothers and sisters and asked their opinion about informing them. Slightly more than half of the respondents were in favour of referring them to a genetic centre to seek the information they need (table 4).

\section{Discussion}

We evaluated the attitudes towards predictive testing for HD in a group of young women. This sample can not be considered as a random sample of the general population in Belgium as they were female, slightly more educated, and probably more interested in health issues than the population at large. However, we feel that the findings of this special group can give insight into public attitudes towards predictive testing for incurable late onset diseases in the near future.

About half of the group of young women expressed interest in a predictive test in the hypothetical situation of a $50 \%$ risk for HD. The fact that a rather large proportion did not know whether or not they would make use of a predictive test reflects the unfamiliarity and doubts about these issues. The above results show that about one quarter of the women would prefer uncertainty to certainty. In other words, they would prefer 'not to know'. For them, living with the certainty that, one day, a progressively debilitating disease for which no treatment is available will strike seemed to be unbearable. This underlies the importance of the right not to know. De Wert ${ }^{18}$ stated that discussion about the implications of the right not to know is urgent because predictive testing will soon become possible for a wide range of late onset diseases. This also emphasises the need for an intense multidisciplinary approach and close follow up of those who do want to know. 9

The sample studied was very reluctant to inform their employer or insurer about the results of predictive tests, but not their partner, children, or general practitioner. This finding is not completely compatible with observations in families with a genetic disease. With regard to $\mathrm{HD}$, it is our experience that informing the children about their genetic risk proved to be a hard job for almost all parents. Therefore, some parents are inclined to postpone informing their children about the disease and the risk. Informing brothers and sisters about their increased genetic risk or referring them to a genetic centre seemed acceptable for most of the women in this study. The experiences in the context of the predictive test for HD in Leuven are somewhat different: we observed a taboo about the risk and the predictive test within several families. This is the major reason why the dynamics of family and partner relationships should be taken into account in genetic counselling in general and in counselling for predictive testing in particular. ${ }^{8}$

Prenatal testing for late onset diseases in general was considered acceptable by $50 \%$ of the women. About one quarter of the total 
group of respondents would terminate a pregnancy should they be pregnant with 'a child who would get a late onset disease (at 35 to 50 years), involving physical and mental deterioration'. Other studies ${ }^{1119}$ reported that a proportion of those who would want prenatal testing (for HD) would not choose to terminate a pregnancy with an affected fetus. "As a result, it is likely that many children will grow up knowing, or learn, that they will eventually develop HD. The psychological impact of this information on the child is unknown". ${ }^{6}$

The majority of the group seemed to perceive genetic counselling as an opportunity rather than as a threat. Counselling was by about two-thirds of the group perceived as a means to gain more control and certainty about their future, especially about their offspring. Having more control over the health of their offspring was perceived as the most important advantage of genetic counselling by almost three-quarters of the subjects. Preventing suffering of the parents as well as of the handicapped child was also considered as an advantage of genetic counselling. As Van den Berghe ${ }^{2}$ stated: "Man in this society of today can no longer find any sense in suffering, especially when it hits him, on a genetic basis, in his existential prolongation which is the child." The danger of stigmatisation was perceived as a potential disadvantage by nearly two-thirds of the respondents. Getting information one can not change, anxiety, and the possibility of misuse of scientific genetic research were also considered as potential disadvantages by more than half of the group. In general, the advantages of genetic counselling were considered to outweigh the disadvantages.

The attitudes towards predictive testing were systematically associated with perceiving 'having more certainty about the future' as an advantage of genetic counselling and with rejecting 'knowing everything in advance' as a disadvantage. The possibility of having (some) certainty about the future and the need to know things in advance seem to play an important stimulating role in the attitudes towards predictive tests. It would be interesting to explore the personality profile corresponding with a person's need for certainty and with the need to know things in advance. This exploration may also be relevant to future predictive testing for other types of diseases, in particular when therapeutic interventions are available after a test result or when post-test changes in behaviour or life style can decrease the risk of developing symptoms. Nevertheless we should keep in mind that knowing the consequences of specific behavioural patterns does not guarantee that the necessary behavioural changes will be made.

The Centre for Family Science in Brussels is acknowledged for its participation in this study. We are very grateful to all students as well as to the teachers and the director, Mrs G Jennes. This project was supported by the Inter-University Network for Fundamental Research sponsored by the Belgian Government (1991-1995).
1 Hill EC. Your morality or mine? An inquiry into the ethic of human reproduction. Am $\mathcal{J}$ Obstet Gynecol 1986;154:1173-80.

2 Van den Berghe $\mathbf{H}$. Impact of genetics on society. In Evers-Kiebooms G, Cassiman JJ, Van den Berghe $\mathbf{H}$ d'Ydewalle G, eds. Genetic risk, risk perception and decision making. March of Dimes, Birth Defects. New York: Alan R Liss, 1987;23:1-5.

3 Blumberg B. The emotional implications of prenatal diagnosis. In: Emery A, Pullen I, eds. Psychological aspects of genetic counselling. London: Academic Press, 1984.

4 Thomassen-Brepols L. Psychological implications of fetal diagnosis and therapy. Fetal Ther 1987:2:169-74.

5 Evers-Kiebooms G, Swerts A, Van den Berghe H. Psychological aspects of amniocentesis: anxiety feelings in three different risk groups. Clin Genet 1988;33:196-206.

6 Bird SJ. Genetic testing for neurologic diseases. A rose with thorns. Neurol Clin 1989;7:859-70.

7 Marteau TM. Psychological implications of genetic screening. In: Evers-Kiebooms G, Fryns JP, Cassiman JJ, Van den Berghe $\mathrm{H}$, eds. Psychosocial aspects of genetic counsel ing. March of Dimes, Birth Defects. New York: Wiley, 1992;28:185-90.

8 Demyttenaere K, Evers-Kiebooms G, Decruyenaere $M$ Pitfalls in counseling for predictive testing in Huntingto disease. In: Evers-Kiebooms G, Fryns JP, Cassiman JJ, Van den Berghe $\mathrm{H}$, eds. Psychosocial aspects of genetic counseling. March of Dimes, Birth Defects. New York: Wiley, 1992;28:105-12.

9 Evers-Kiebooms G. Predictive testing for Huntington's disease in Belgium. $f$ Psychosom Obstet Gynecol 1990;11:61-72.

10 Sujansky E, Beeler Kreutzer S, Johnson AM, et al. Attitudes of at-risk and affected individuals regarding presymptomatic testing for autosomal dominant polycystic symptomatic testing for autosomal dominant pol

11 Kessler S, Field T, Worth L, Mosbarger H. Attitudes of persons at risk for Huntington disease toward predictive testing. Am $\mathcal{f}$ Med Genet 1987;26:259-70.

12 Kolata G. Genetic screening raises questions for employers and insurers. Science 1986;238:317-19.

3 Huggins $M$, Bloch $M$, Kanani S, et al. Ethical and legal dilemmas arising during predictive testing for adult-onse disease: the experience of Huntington disease. Am $\mathcal{f ~ H u m}$ Genet 1990;47:4-12.

14 Wertz DC, Fletcher JC, Mulvihill JJ. Medical geneticists confront ethical dilemmas: cross-cultural comparisons among 18 nations. Am $\mathcal{F}$ Hum Genet 1990;46:1200-13.

15 Gillon A. Genetic counselling, confidentiality, and the medical interest of relatives. $\mathscr{f}$ Med Ethics $1988 ; 14: 171-2$

16 Wertz DC, Fletcher JC. An international survey of attitudes of medical geneticists towards mass screening and access of medical geneticists towards mass screening

17 Decruyenaere M, Evers-Kiebooms G, Van den Berghe $H$ Community knowledge of human genetics. In: EversKiebooms G, Fryns JP, Cassiman JJ, Van den Berghe $\mathrm{H}$ eds. Psychosocial aspects of genetic counseling. March of Dimes, Birth Defects. New York: Wiley, 1992;28:167-84

18 De Wert G. Predictive testing for Huntington disease and the right not to know. Some ethical reflections. In: EversKiebooms G, Fryns JP, Cassiman JJ, Van den Berghe $\mathbf{H}_{\text {, }}$ eds. Psychosocial aspects of genetic counseling. March of Dimes, Birth Defects. New York: Wiley, 1992;28:133-8.

19 Meissen GJ, Berchek RL. Intended use of predictive testing by those at risk for Huntington disease. Am $\mathcal{F}$ Med Genet 1987;26:283-93.

Appendix 1 Informative text on $H D$.

Huntington's disease is a genetic disease, which progressively affects parts of the brain. The principal features are physical and mental deterioration. The first symptoms usually appear between 35 and 50 years. The majority of the patients die 10 to 20 years later.

Huntington's disease is an autosomal dominant disease. That means that all children of an affected parent, boys as well as girls, have a $50 \%$ risk (thus 1 chance in 2 ) of developing the disease. The uncertainty about their own and the children's future is very burdensome.

For some years, a predictive test has been available. Long before the manifestation of the first symptoms, it is possible to find out whether or not one has inherited the anomalous gene by means of a blood sample. If one has not inherited the anomalous gene, then one knows with certainty that one will not get the disease. If one has inherited the anomalous gene, then one knows with certainty that one will get the disease and that one can pass the disease on to the children. 
Appendix 2 Prenatal testing for late onset diseases.

What is your opinion about prenatal testing to predict the serious diseases that the unborn child will get when grown up?

(1) This is completely unacceptable.

(2) This is fairly unacceptable.

(3) I don't know.

(4) This is fairly acceptable.

(5) This is completely acceptable.

Appendix 3 Pregnancy termination.

In which of the following situations would you terminate the pregnancy?

One of the situations was: When pregnant with a child that would get an adult onset disease (at 35 to 50 years), involving physical and mental deterioration.

Appendix 4 Intercorrelations (Kendall-tau) of attitudes towards $(A)$ predictive testing for $H D$, (B) prenatal testing for adult onset diseases, and (C) pregnancy termination should they be pregnant with a child who would get an adult onset disease, involving physical and mental deterioration, with agreeing with the so called advantages and disagreeing with the so called disadvantages of genetic counselling ( $n=151$ to 159).

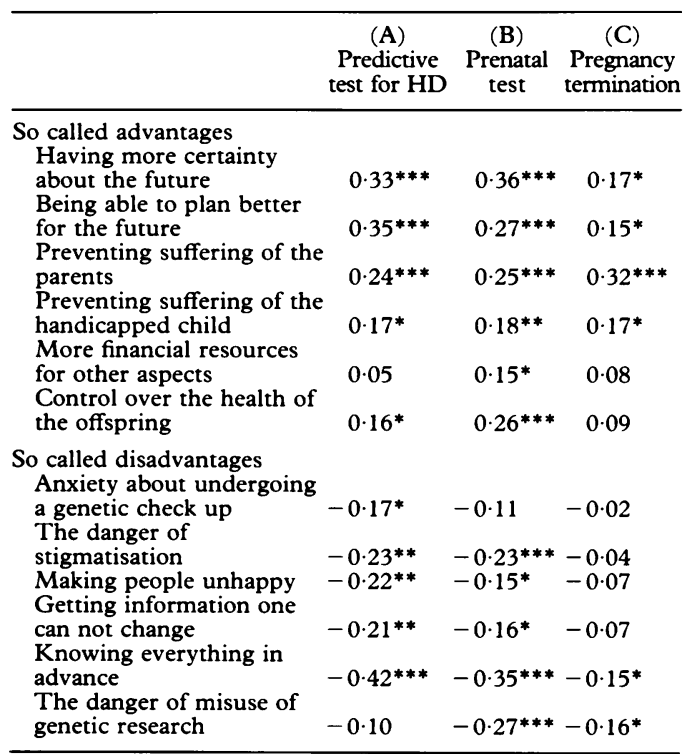

Answer categories:

(A) I would not use it $(=1)$, I don't know $(=2)$, I would use it $(=3)$

(B) See appendix 2

(C) Not terminate $(=1)$, terminate $(=2)$.

Level of significance of the correlation:

* significant at level 0.05 .

** significant at level 0.01 .

***significant at level 0.001 